\title{
Analysis of PBDEs in Soil, Dust, Spiked Lake Water, and Human Serum Samples by Hollow Fiber-Liquid Phase Microextraction Combined with GC-ICP-MS
}

\author{
Qin Xiao, Bin Hu, Jiankun Duan, Man He, and Wanqing Zu \\ Department of Chemistry, Wuhan University, Wuhan, China
}

\begin{abstract}
A novel method for the analysis of four polybrominated diphenyl ethers (PBDEs) in environmental and human serum samples based on hollow fiber-liquid phase microextraction (HF-LPME) followed by gas chromatography-inductively coupled plasma mass spectrometric (GC-ICP-MS) detection has been developed. The organic solvent in the porous hollow fiber was first dipped into the sample for extraction at a given time, and the retracted organic phase was introduced into the GC-ICP-MS for analysis. The addition of methanol has a strong effect on the HF-LPME extraction efficiency. Other significant parameters affecting the extraction efficiency of HF-LPME were also studied. HF-LPME was effective to isolate the analytes from the complex matrix. Under the optimized conditions, the detection limits of the proposed method varied from 15.2 to $40.5 \mathrm{ng} / \mathrm{L}$. In general, the relative standard deviations (RSDs) were less than $10 \%$. Good linearity was obtained with the correlation coefficients all better than 0.999 . The proposed method is simple, quick, few microliters of organic solvent required, and is especially suitable for the analysis of the real sample with small amount available. The overall process of HF-LPME with GC-ICP-MS was applied successfully for the determination of polybrominated diphenyl ethers (PBDEs) in environmental and spiked human serum samples, and the results were satisfactory. (J Am Soc Mass Spectrom 2007, 18, 1740-1748) (C 2007 American Society for Mass Spectrometry
\end{abstract}

$\mathrm{F}$ rom the beginning of the 1970s, polybrominated diphenyl ethers (PBDEs) have been widely used for many years as flame retardants in a variety of commercial products, such as furniture, textiles, plastics, paints, and electronic appliances because of their low cost and high-performance. There exist, theoretically, 209 congeners of PBDEs depending on the number and place of the bromine substituents on the phenyl rings. PBDEs are used as additive flame retardants and are not covalently bound to the materials. They may therefore leach from the products and be released into the environment [1]. The implementation of the EU directives on waste electrical and electronic equipment (WEEE) and on the restriction of hazardous substance (RoHS) has drawn much attention to the environmental occurrence and toxicity of PBDEs used extensively in electrical and electronic equipments.

Hence, there has been an increasing interest in developing new sample pretreatment approaches for determining this class of persistent contaminants. The main sample preparation methods for PBDEs analysis include liquid-liquid extraction (LLE) [2], solid-phase extraction (SPE) [3, 4], pressurized liquid extraction

Address reprint requests to Professor B. Hu, Department of Chemistry, Wuhan University, Wuhan 430072, People's Republic of China. E-mail: binhu@whu.edu.cn
(PLE) [5, 6], and microwave assisted extraction (MAE) [7]. Especially in relation to LLE, it is time-consuming and hazardous to health due to the large-volume of toxic solvents used. The new sample preparation methods for PBDEs analysis include solid-phase microextraction (SPME) and the recently developed stir bar sorptive extraction (SBSE). Both of the techniques, SPME and SBSE, require specialized apparatus, and the SPME fibers or the SBSE stir bars are expensive and lifetime limited. In addition, sample carry-over between runs has been reported with SPME [8,9] or SBSE [10] and, unless an extra-cleaning step is introduced in the sampling protocol, the results are invalid.

To reduce the consumption of organic solvents, single drop microextraction (SDME) was introduced in $1996[11,12]$. This relatively new technique is performed by suspending a microliter drop of organic solvent on the tip of a microsyringe immersed in the stirred aqueous solution. Compared with LLE and SPE, LPME gives a comparable and satisfactory sensitivity and much better enrichment of analytes, and the consumption of solvent is significantly reduced by up to several hundred or several thousand times. The LPME technique is simple, fast, and inexpensive. However, LPME based on hanging droplets is not very robust, and the microdrop suspended on the needle of microsy- 
ringe is easily dislodged during extraction, especially the case when samples are stirred vigorously.

Pedersen-Bjergaard and Rasmussen introduced an alternative concept for hollow fiber-liquid phase microextraction (HF-LPME) using porous hollow fibers made of polypropylene [13]. Using a hollow fiber to protect the extraction solvent might be an effective method to solve the aforementioned problems. The hollow fiber is low-cost and disposable. Compared with SPME and SBSE, HF-LPME does not require specialized apparatus, is inexpensive, and could avoid the problems of limited lifetime and sample carry-over. In HF-LPME, the needle of the syringe was inserted into a hollow fiber segment, and the injected organic solvent was full of the lumen of the hollow fiber. Then, the hollow fiber was immersed in the aqueous solution. After extraction, the solvent in the fiber was retracted into the syringe and the hollow fiber membrane discarded. Analytes were extracted from aqueous samples through a thinlayer of organic solvent immobilized within the pores of a porous hollow fiber, and into an acceptor solution inside the lumen of the hollow fiber. The micro-extract is not in direct contact with the sample solution, so the samples may be stirred or vibrated vigorously without any loss of the micro-extract. Thus, HF-LPME is a more robust and reliable alternative to LPME.

HF-LPME may provide high analyte preconcentration and excellent sample clean-up with a short extraction time. Reproducibility was improved significantly compared with that of SDME conducted without the use of the hollow fiber. It has a widespread application for the analysis of organic pollutants in a variety of environmental and biological samples [14-17].

Owing to the vapor pressures and polarity of PBDEs, GC is the most widely used technique to analyze the various congeners, by using electron capture detection (ECD), electron ionization-mass spectrometry (EI-MS), or electron capture negative ionization-mass spectrometry (ECNI-MS) as detector [18, 19]. In general, GC-EI-MS provides better structural information, but it is affected by different chlorinated interferences. ECD and ECNI-MS techniques are not as selective as EI-MS for the analysis of lower brominated congeners. GC-NICI-MS eliminated chlorinated interferences and also showed better sensitivity, but the use of NICI provided less structural information than that provided by EI.

A new possibility for element-specific GC detection is inductively coupled plasma mass spectrometry (ICP-MS). The hyphenation of GC with ICP-MS has been presented as an attractive alternative to analyze the PBDEs in the literatures [20, 21]. ICP-MS has good sensitivity and selectivity compared with ECD or MS detection, which may cause identification or interference problems, especially in the presence of other compounds containing sulfur or chlorine. In ICP-MS, bromine ions are detected, so it eliminates chlorinated interferences and also shows better sensitivity. Due to ionization in plasma, there are fewer possible matrix interferences per analyte mass than other MS techniques. ICP-MS is a good choice as an element-specific detector for PBDE analysis when the structural information is not required.

In this work, HF-LPME was introduced as a simple and fast sample pretreatment method for the determination of PBDEs with GC-ICP-MS detection. Both advantageous characteristics of HF-LPME and GCICP-MS will be useful for the extraction and further analysis of PBDEs in some complex matrix (e.g., serum, soil, etc.). 2,4,4'-tribromodiphenyl ether (BDE-28), 2,2', 4,4' -tetrabromodiphenyl ether (BDE-47), 2,2',4,4',5pentabromodiphenyl ether (BDE-99), and $2,2^{\prime}, 4,4^{\prime}, 6-$ pentabromodiphenyl ether (BDE-100) were used as the target analytes. The experimental parameters affecting the HF-LPME extraction of PBDEs were also investigated and optimized. The developed method was applied successfully to the determination of PBDEs in human serum and environmental samples.

\section{Experimental}

\section{Reagents and Materials}

Analytical standards including 2,4,4' -tribromodiphenyl

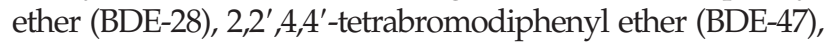
$2,2^{\prime}, 4,4^{\prime}, 5$-pentabromodiphenyl ether (BDE-99), and $2,2^{\prime}, 4,4^{\prime}, 6$-pentabromodiphenyl ether (BDE-100) at a concentration of $50 \mu \mathrm{g} / \mathrm{mL}$ were separately prepared in isooctane. These were purchased from AccuStandard (New Haven, CT); 2,2',4,4',5,5'-hexabromodiphenyl (BB-153) was used as internal standard (I.S.), and it was also purchased from AccuStandard. A stock solution containing all studied compounds at a concentration of $1 \mu \mathrm{g} / \mathrm{mL}$ in acetone was prepared and stored in darkness at $-10^{\circ} \mathrm{C}$. Working solutions used in further studies were prepared fresh with doubly distilled water to the required concentrations, and stored in refrigerator at $4^{\circ} \mathrm{C}$ in the dark.

Solvents used in the studies including decane, oxylene, n-octanol, diphenyl ether, chlorobenzene, and so on, were of analytical reagent grade. Doubly distilled water was used throughout this work. Glassware was rinsed with doubly distilled water, decontaminated overnight in ethanol and air-dried before use.

A $10 \mu \mathrm{L}$ microsyringe (Gaoge, Shanghai, China) was rinsed at least 5 times with the extraction solvent before use. The Q3/2 Accurel polypropylene hollow fiber was purchased from Membrana $\mathrm{GmbH}$ (Wuppertal, Germany). The i.d. of the hollow fiber was $600 \mu \mathrm{m}$, the thickness of the wall was $200 \mu \mathrm{m}$, and the pore size was $0.2 \mu \mathrm{m}$. A hollow fiber was cut into $15 \mathrm{~mm}$ segments. The approximate internal volume of each segment was about $4 \mu \mathrm{L}$, which was suitable for the amount of extraction solvent used in this work. The hollow fiber was ultrasonically cleaned in acetone and air-dried before use. 


\section{Preparation of Samples}

A pooled healthy human serum sample used for the experiment was obtained from the Hospital of Wuhan University (Wuhan, China), and stored at $-10{ }^{\circ} \mathrm{C}$. The sample was spiked with PBDEs at two levels of 10 and $50 \mathrm{ng} / \mathrm{mL}$, respectively, and BB-153 was added as the internal standard, then kept in the dark at room temperature for about half an hour. Three and $15 \mathrm{~mL}$ methanol were added to $1 \mathrm{~mL}$ fortified serum sample, and then diluted to 10 and $50 \mathrm{~mL}$ with doubly distilled water, respectively.

A water sample was obtained from East Lake $(\mathrm{Wu}-$ han, China), and stored at $-10^{\circ} \mathrm{C}$. The spiked water samples were obtained by spiking $1 \mathrm{ng} / \mathrm{mL}$ of PBDEs, and BB-153 was added as the internal standard, then $3 \mathrm{~mL}$ methanol was added to the $7 \mathrm{~mL}$ spiked water sample.

A soil sample was obtained from the landfill of Beiyang Bridge (Wuhan, China), and a dust sample was obtained from a used computer (made in China); they were stored at $-10^{\circ} \mathrm{C} ; 0.5 \mathrm{~g}$ of the soil sample and $0.05 \mathrm{~g}$ of the dust sample were fortified with PBDEs and BB-153 (I.S.), then kept in the dark at room temperature for about $2 \mathrm{~h}$. The sample was extracted with $3 \mathrm{~mL}$ methanol for $30 \mathrm{~min}$ by sonication, centrifuged at 3500 rpm for $5 \mathrm{~min}$, and the supernatant was diluted to 10 $\mathrm{mL}$ with water.

All the above sample analyses were repeated three times.

\section{HF-LPME Procedures}

In the optimal operational conditions, HF-LPME was carried out in a $4 \mathrm{~mL}$ vial containing $3 \mathrm{~mL}$ sample solution (adding 30\% methanol) with a stir bar. The vial was placed on a 85-2A constant temperature magnetic stirrer (Ronghua, Jiangsu, China) and maintained at $40{ }^{\circ} \mathrm{C}$. First, $4 \mathrm{uL}$ of organic solvent was withdrawn into the microsyringe. Then the needle tip was inserted into the hollow fiber and immersed in the organic solvent for about $5 \mathrm{~s}$ to impregnate the pores with the organic solvent. The organic solvent in the syringe was injected completely into the hollow fiber. The fiber, together with the microsyringe needle, was placed into the sample solution. The magnetic stirrer was switched on to start the extraction, allowing the sampling process for $20 \mathrm{~min}$. Once finished, the solvent in the hollow fiber was retracted into the microsyringe and the hollow fiber was discarded. Finally, $1 \mu \mathrm{L}$ analyte-enriched solvent was immediately injected into GC injector for GC-ICP-MS analysis.

\section{GC-ICP-MS Detection}

An Agilent 6890 (Agilent Technologies, Santa Clara, CA) gas chromatograph was used for the separation. The GC was interfaced to an Agilent 7500a ICP-MS (Agilent Technologies, Takatura, Japan) through a
GC-ICP-MS interface (Agilent Technologies), which featured a temperature controlled transfer-line, and a stainless steel injector tip was used for the hyphenation of GC and ICP-MS. The GC column was carried from the oven directly into the ICP torch to avoid condensation in the connection between the column and the fused silica capillary. A heated transfer line designed by Agilent Technologies was utilized. Two auxiliary units heat the transfer line and the power for these is supplied by the gas chromatograph. The transfer line temperature was maintained at $280^{\circ} \mathrm{C}$. These have been detailed elsewhere [20,22]. To verify the conditions of the instrument, a normal instrument tune was run for ICP-MS before switching to GC. The ICP-MS conditions were optimized using the continual signal of the ${ }^{126} \mathrm{Xe}$ isotope. This signal served [1] to tune the MS spectrometer, [2] to adjust the position of the transfer line (fused silica capillary) in the torch, and [3] to optimize ICP operating parameters. These parameters were optimized daily with the objective to reach the maximum sensitivity for the ${ }^{126} \mathrm{Xe}$ isotope. For determination of the PBDEs, isotopes ${ }^{79} \mathrm{Br}$ and ${ }^{81} \mathrm{Br}$ were monitored by ICP-MS. Control and operation of the system was achieved using the Agilent 7500 ICP-MS ChemStation software. The optimized conditions for GC-ICP-MS were listed in Table 1.

\section{Results and Discussion}

\section{Hollow Fiber-Liquid Phase Microextraction (HF-LPME)}

To obtain the best sensitivities, different parameters affecting HF-LPME including solvent type, methanol addition, stirring rate, extraction time, temperature, and ionic strength have been optimized.

Table 1. Instrument operating parameters of GC-ICP-MS

\begin{tabular}{|c|c|}
\hline \multicolumn{2}{|l|}{$\mathrm{GC}$} \\
\hline Column & $\begin{array}{l}\text { HP-5 (30 m } \times 0.32 \mathrm{~mm} \text { i.d. and } 0.25 \\
\mu \mathrm{m} \text { film thickness, } 5 \% \text { phenyl and } \\
95 \% \text { methyl-polysiloxane })\end{array}$ \\
\hline Carrier gas & Helium \\
\hline Carrier gas flow rate & $2.0 \mathrm{~mL} / \mathrm{min}$ \\
\hline Oven temperature & $\begin{array}{c}150^{\circ} \mathrm{C} \text { initial ramped at } 20^{\circ} \mathrm{C} / \mathrm{min} \\
\text { to } 280^{\circ} \mathrm{C} \text { and held for } 4.5 \mathrm{~min}\end{array}$ \\
\hline Injection volume & $1 \mu \mathrm{L}$ \\
\hline Injector temperature & $250^{\circ} \mathrm{C}$ \\
\hline Injection mode & Splitless \\
\hline \multicolumn{2}{|l|}{ GC-ICP-MS interface } \\
\hline $\begin{array}{l}\text { Transfer line/injector } \\
\text { temperature }\end{array}$ & $280^{\circ} \mathrm{C}$ \\
\hline \multicolumn{2}{|l|}{ ICP-MS } \\
\hline Rf power & $500 \mathrm{~W}$ \\
\hline $\begin{array}{l}\text { Ar plasma gas flow } \\
\text { rate }\end{array}$ & $15.0 \mathrm{~L} / \mathrm{min}$ \\
\hline $\begin{array}{l}\text { Ar carrier gas flow } \\
\text { rate }\end{array}$ & $1.08 \mathrm{~L} / \mathrm{min}$ \\
\hline $\begin{array}{l}\text { Dwell time } \\
\text { Isotopes monitored }\end{array}$ & $\begin{array}{l}0.1 \mathrm{~s} \text { per isotope } \\
{ }^{79} \mathrm{Br} \text { and }{ }^{81} \mathrm{Br}\end{array}$ \\
\hline
\end{tabular}


Solvent type. Careful attention should be paid to the selection of the extraction solvent, which is very important for achieving good selectivity of the target compounds. The solvent used for the HF-LPME must have low water solubility, high extraction efficiency, and low level of toxicity, and should be compatible with the hollow fiber. Several different organic solvents, such as decane, o-xylene, $n$-octanol, diphenyl ether, and chlorobenzene were investigated in this study. The results showed that decane gave the best extraction efficiency for all the analytes of PBDEs (BDE-28, BDE-47, BDE-99, and BDE-100). The most possible reason may be that PBDEs are lipophilic, and the principle "like dissolves like" is applied here. Besides, the toxicity level of decane is much lower. Therefore, decane was chosen as the extraction solvent for HF-LPME.

Methanol addition. In the extraction of apolar compounds such as PBDEs, their adsorption on the glass walls may result in the lower extraction efficiency either with SPME or SBSE in other studies [23, 24]. Adding methanol to the sample could effectively avoid the adsorption of PBDEs, which has been evaluated in a previous work by Llorca-Porcel et al. [25]. In this work, the effect of methanol addition was also evaluated by varying the amount of methanol in the range of $0 \%$ to $30 \%$, and the experimental results were shown in Figure 1. It was found that the analytical responses of all PBDEs increased with methanol addition increasing from $0 \%$ to $30 \%$. Adding more methanol to the sample, the dissolution of the organic solvent would increase, thus influencing the stability of extraction, especially for prolonged extraction times. Hence, 30\% methanol was added to the sample for subsequent analyses.

Stirring rate. According to the film theory of convectivediffusive mass transfer, the diffusion coefficient in the aqueous phase increases with increasing the stirring rate because faster agitation can decrease the thickness

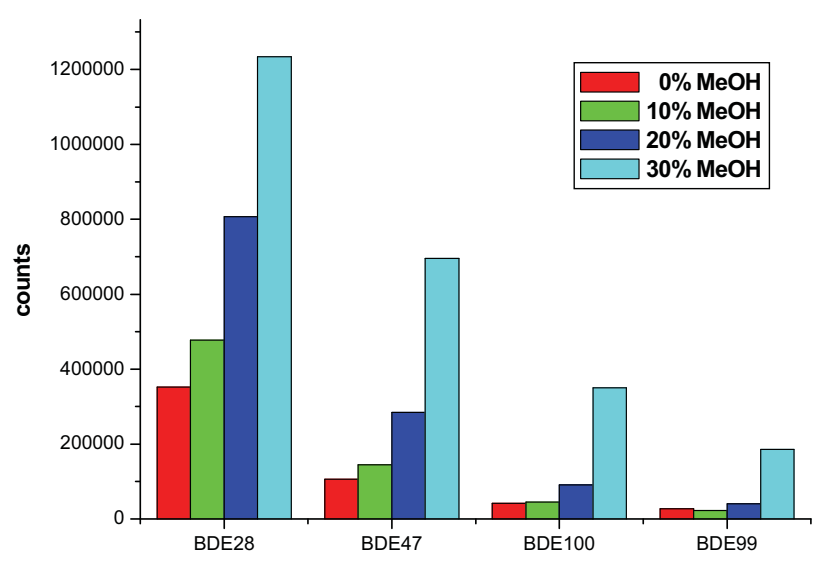

Figure 1. Effect of methanol addition on HF-LPME. $10 \mathrm{~min}$ extraction with $3 \mathrm{~mL}$ of $5 \mathrm{ng} / \mathrm{mL}$ sample solution containing $0 \%$ to $30 \%$ methanol at a stirring rate of $1000 \mathrm{rpm}\left(40^{\circ} \mathrm{C}\right)$, using decane as the extraction solvent, injection volume $1.0 \mu \mathrm{L}$.

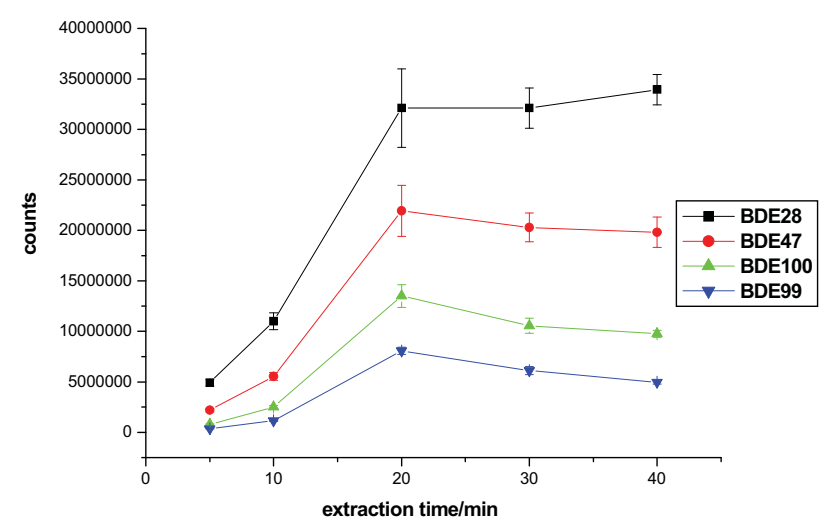

Figure 2. Effect of extraction time on HF-LPME $(n=3) ; 3 \mathrm{~mL}$ of $5 \mathrm{ng} / \mathrm{mL}$ sample solution containing 30\% methanol at $1000 \mathrm{rpm}$ $\left(40^{\circ} \mathrm{C}\right)$, using decane as the extraction solvent, injection volume $1.0 \mu \mathrm{L}$.

of the diffusion film in the aqueous phase [26, 27]. Thus, extraction efficiency is enhanced and the time to thermodynamic equilibrium is reduced, as the partitioning equilibrium of analytes in the two phases is established more rapidly. The effect of the stirring rate on the extraction efficiency of target analytes was studied, and the results indicated that the extraction efficiency of all the analytes increased with the increase of stirring rate from 600 to $1200 \mathrm{rpm}$. However, when the stirring rate was $1200 \mathrm{rpm}$, the relative standard deviations were higher than that of $1000 \mathrm{rpm}$. The possible reason for this may be higher speed agitation, which may lead to the dissolution loss of the organic phase. Hence, a stirring rate of $1000 \mathrm{rpm}$ was selected for the further work.

Extraction time. HF-LPME is based on the equilibrium of analytes between the two system phases: the organic solvent in the hollow fiber, and the sample solution. Usually, prolonging the extraction time could improve the extraction efficiency for stirring could accelerate the mass transfer and diffusion between the two system

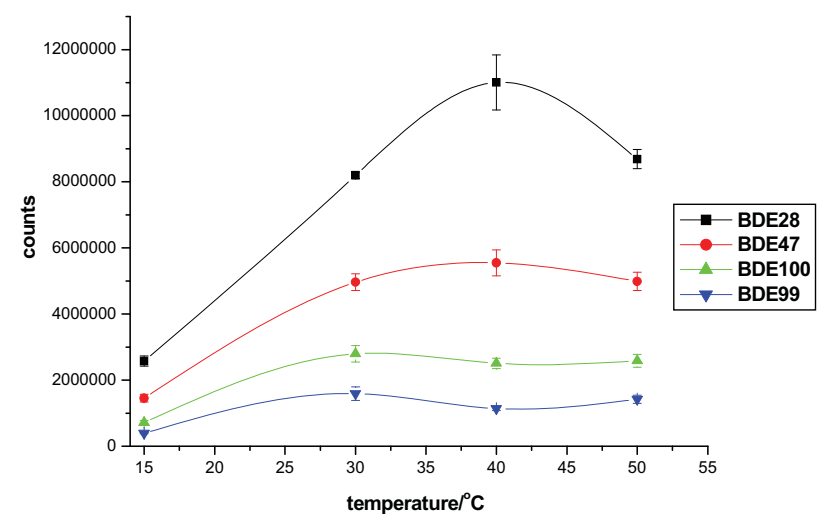

Figure 3. Effect of sample temperature on HF-LPME $(n=3) ; 10$ min extraction with $3 \mathrm{~mL}$ of $5 \mathrm{ng} / \mathrm{mL}$ sample solution containing $30 \%$ methanol at a stirring rate of $1000 \mathrm{rpm}$, using decane as the extraction solvent, injection volume $1.0 \mu \mathrm{L}$. 
Table 2. Analytical performance data for PBDEs by HF-LPME with GC-ICP-MS detection

\begin{tabular}{lcccccc}
\hline & & & & & \multicolumn{2}{c}{$\mathrm{RSD}^{\mathrm{a} / \%}$} \\
\cline { 3 - 7 } PBDEs & Linearity $\mathrm{ng} / \mathrm{mL}$ & $\mathrm{R}$ & Enrichment factor & Detection Limit ng/L & Retention time & Peak area \\
\hline \hline BDE-28 & $0.2-20$ & 0.9999 & 83 & 15.2 & 0.07 & 6.8 \\
BDE-47 & $0.2-20$ & 0.9999 & 54 & 32.8 & 0.11 & 5.1 \\
BDE-99 & $0.2-20$ & 0.9990 & 30 & 40.5 & 0.02 & 8.3 \\
BDE-100 & $0.2-20$ & 0.9999 & 38 & 24.5 & 0.06 \\
\hline
\end{tabular}

${ }^{\mathrm{a}} \mathrm{C}=5 \mathrm{ng} / \mathrm{mL}, n=3$.

phases. Figure 2 was the effect of extraction time on the extraction efficiency of four PBDEs with the extraction time varying from 0 to $40 \mathrm{~min}$ and a sample temperature of $40^{\circ} \mathrm{C}$. As could be seen, the extraction efficiency of four PBDEs increased with the increase of extraction time in $20 \mathrm{~min}$, and kept practically constant with further increase of the extraction time to $40 \mathrm{~min}$. HFLPME will attain the maximum sensitivity when the equilibrium between aqueous and organic phase has been achieved. So, a 20 min extraction time was deemed to be sufficient for subsequent experiments.

Temperature. Temperature has a significant effect on both kinetics and thermodynamics of the extraction process. In our study, experiments were carried out with sample solutions at 15 to $50{ }^{\circ} \mathrm{C}$ (Figure 3). It was found that the extraction efficiency of BDE-28 increased with the temperature increasing from $15^{\circ} \mathrm{C}$ to $40^{\circ} \mathrm{C}$. When the sample temperature increased to $50{ }^{\circ} \mathrm{C}$, the extraction efficiency of BDE-28 decreased significantly. While for the other three PBDEs (BDE-47, BDE-99, and BDE-100), the extraction efficiency increased from $15^{\circ} \mathrm{C}$ to $30^{\circ} \mathrm{C}$, and remained almost constant from $30^{\circ} \mathrm{C}$ to $50{ }^{\circ} \mathrm{C}$.

There were two opposing effects that influenced HF-LPME process. On one hand, an increase in extraction temperature would increase the diffusion coefficient and accelerate the mass transfer between the organic film and aqueous sample film and, therefore, improve extraction efficiency. On the other hand, the solubility of the analytes in water would also increase, so the distribution constants of analytes to the organic phase would decrease with increasing temperature, leading to a decrease in the extraction efficiency. When the temperature was lower than $40^{\circ} \mathrm{C}$, the effect of increasing the diffusion coefficient dominated; however, when the temperature was higher than $40{ }^{\circ} \mathrm{C}$, the effect of decreasing the distribution constants dominated. This may be the possible reason for the above results for PBDEs. Furthermore, it will result in the formation of air bubbles at $50{ }^{\circ} \mathrm{C}$ and make it difficult to draw back the organic solvent from the hollow fiber. In further measurements, the sample vial temperature of $40{ }^{\circ} \mathrm{C}$ was used.

Ion strength. For HF-LPME in aqueous solution, the addition of salt (such as $\mathrm{NaCl}$ or $\mathrm{Na}_{2} \mathrm{SO}_{4}$ ) can decrease the solubility of analytes and enhance their partitioning into the organic phase. The effect of salt on the extraction was also investigated in this study. The experiments were carried out by adding $\mathrm{NaCl}$ into the sample solution in the range of $0 \%$ to $20 \%(\mathrm{~m} / \mathrm{V})$. It was found that the extraction efficiency of BDE-28 and BDE-47 increased slightly when the $\mathrm{NaCl}$ concentration increased from $0 \%$ to $5 \%$, while for BDE-99 and BDE-100, the extraction efficiency remained nearly constant with the increase of $\mathrm{NaCl}$ concentration from $0 \%$ to $5 \%$. When more salt was added into the sample, a decrease

Table 3. Comparison of the methods in the literature for the determination of PBDEs

\begin{tabular}{|c|c|c|c|c|c|c|}
\hline Real sample & Sample preparation ${ }^{a}$ & $\begin{array}{c}\text { Extraction } \\
\text { time }\end{array}$ & $\begin{array}{l}\text { Detection } \\
\text { technique }^{\mathrm{b}}\end{array}$ & $\begin{array}{c}\text { Inject } \\
\text { volume }\end{array}$ & LODs & Ref. \\
\hline $\begin{array}{l}\text { human serum, water, } \\
\text { soil, and dust }\end{array}$ & HF-LPME & $20 \mathrm{~min}$ & GC-ICP-MS & $1 \mu \mathrm{L}$ & $15.2-40.5 \mathrm{ng} / \mathrm{L}$ & This work \\
\hline sewage sludge & LLE & $18 \mathrm{~h}$ & GC-ICP-MS & $2 \mu \mathrm{L}$ & $90-200^{\circ} \mathrm{ng} / \mathrm{L}$ & {$[20]$} \\
\hline water samples & SBSE & $25 \mathrm{~h}$ & GC-MS & - & $0.3-7.8 \mathrm{ng} / \mathrm{L}$ & [25] \\
\hline water samples & HS-SPME & $30 \mathrm{~min}$ & GC-MS-MS & - & $0.02-0.06 \mathrm{ng} / \mathrm{L}$ & [29] \\
\hline water samples & HF-MMLLE & $60 \mathrm{~min}$ & GC-MS & $2 \mu \mathrm{L}$ & $0.3-1.1 \mathrm{ng} / \mathrm{L}$ & {$[30]$} \\
\hline solid samples & HS-SPME & $60 \mathrm{~min}$ & GC-MS-MS & - & $5.4-109 \mathrm{pg} / \mathrm{g}$ & {$[31,32]$} \\
\hline food samples & SPE with HPLC fractionation & - & GC-MS-MS & $4 \mu \mathrm{L}$ & $80-680 \mathrm{ng} / \mathrm{L}$ & [33] \\
\hline sediments & MAE & $24 \min$ & GC-ITMS & $70 \mu \mathrm{L}$ & $4-20 \mathrm{pg} / \mathrm{g}$ & [34] \\
\hline birds & SPE & - & GC-MS & - & 0.1 and $0.4 \mathrm{ng} / \mathrm{g}$ & [35] \\
\hline
\end{tabular}

aHF-LPME: hollow fiber liquid phase microextraction; LLE: liquid liquid extraction; SBSE: stir bar sorptive extraction; HS-SPME: headspace-solid phase microextraction; HF-MMLLE: hollow-fiber microporous membrane liquid-liquid extraction; SPE: solid phase extraction; MAE: microwaveassisted extraction.

${ }^{b} \mathrm{GC}$ : gas chromatography; ICP-MS: inductively coupled plasma mass spectrometry; MS: mass spectrometry; MS-MS: tandem mass spectrometry; ITMS: ion trap mass spectrometry.

Instrument detection limits. 
Table 4. Concentrations of PBDEs and recoveries in human serum

\begin{tabular}{|c|c|c|c|c|c|}
\hline \multirow[b]{2}{*}{ PBDEs } & \multirow[b]{2}{*}{ Added ng/mL } & \multirow[b]{2}{*}{ Found ng/mL } & \multirow[b]{2}{*}{ Recovery \% } & \multicolumn{2}{|c|}{$\mathrm{RSD}^{\mathrm{a} / \%}$} \\
\hline & & & & Retention time & Peak area \\
\hline \multirow[t]{3}{*}{ BDE-28 } & 0 & n.d. ${ }^{b}$ & - & - & - \\
\hline & $10^{c}$ & 11.17 & 111.7 & 0.08 & 7.4 \\
\hline & $50^{d}$ & 48.15 & 96.3 & 0.15 & 1.5 \\
\hline \multirow{3}{*}{ BDE-47 } & 0 & n.d. ${ }^{b}$ & - & - & - \\
\hline & $10^{c}$ & 8.86 & 88.6 & 0.25 & 7.5 \\
\hline & $50^{d}$ & 52.25 & 104.5 & 0.17 & 4.4 \\
\hline \multirow[t]{3}{*}{ BDE-99 } & 0 & n.d. ${ }^{b}$ & - & - & - \\
\hline & $10^{c}$ & 8.85 & 88.5 & 0.06 & 1.3 \\
\hline & $50^{d}$ & 53.10 & 106.2 & 0.03 & 0.4 \\
\hline \multirow{3}{*}{ BDE-100 } & 0 & n.d. ${ }^{b}$ & - & - & - \\
\hline & $10^{c}$ & 8.45 & 84.5 & 0.65 & 6.8 \\
\hline & $50^{d}$ & 52.70 & 105.4 & 0.16 & 5.9 \\
\hline
\end{tabular}

${ }^{a} n=3$.

${ }^{b}$ n.d.: not detected.

'Determined after 10 -fold dilution.

${ }^{\mathrm{d}}$ Determined after 50 -fold dilution.

in extraction efficiency was observed for the four PBDEs. It was assumed that apart from the salting-out effect, the presence of salt caused another effect and changed the physical properties of the extraction film, thus reducing the diffusion rates of the analytes into the organic phase. In addition, a much reduced solubility of PBDEs would probably lead to more forced adsorption of the analytes to the container surface as $\mathrm{NaCl}$ concentration increased. It was also reported that the saltingout effect reduced extraction efficiency of HF-LPME in work of others [17]. To simplify the manipulation, sample direct analysis without the salt addition was employed in this work.

\section{Analytical Performance of HF-LPME-GC-ICP-MS}

Based on the above optimization, the optimal HF-LPME conditions for four PBDEs are: 30\% methanol was added to the sample, decane was used as the extraction solvent, 20 min extraction at $40{ }^{\circ} \mathrm{C}$ with a stirring rate of $1000 \mathrm{rpm}$.

The analytical performance of the proposed method HF-LPME-GC-ICP-MS has been validated through the determination of linearity, limits of detection, and precision with BB-153 as internal standard; each was analyzed in triplicate and the results are listed in Table 2. The linearity of calibration plots was studied over a concentration range of 0.2 to $20 \mathrm{ng} / \mathrm{mL}$ for HF-LPME. All the PBDEs exhibited good linearities, with correlation coefficient ranging from 0.9990 to 0.9999 . The limits of detection (LOD) for the PBDEs of interest were calculated based on background noise and utilized the $3 s_{\text {blank }}$ approach as recommended by IUPAC for spectrochemical measurements [28]. The LODs ranging from $15.2 \mathrm{ng} / \mathrm{L}$ for BDE-28 to $40.5 \mathrm{ng} / \mathrm{L}$ for BDE-99 by HF-LPME-GC-ICP-MS were obtained. The results clearly indicated that, under the present experimental conditions, HF-LPME-GC-ICP-MS is a sensitive and selective technique for the target analytes of PBDEs. To evaluate the precision of the proposed methods, repeatability was estimated under the optimum extraction conditions in all the experiments. The relative standard deviations (RSDs) were from $0.02 \%$ to $0.11 \%$ for retention time and $5.1 \%$ to $9.1 \%$ for peak area.

The enrichment factor, defined as the concentration ratio of the concentration obtained after HF-LPME to the original concentration in the sample. Under optimized conditions, the enrichment factors for the PBDEs were determined; the results are given in Table 2. For BDE-28 (tri-BDE congener) and BDE-47 (tetra-BDE congener), the enrichment factors of 83- and 54-fold could be obtained, while only 30- and 38-fold of enrichment factors were obtained for BDE-99 and BDE-100 (pentaBDE congeners). The enrichment factors for BDE-99 and BDE-100 were smaller than that of BDE-28 and BDE-47; the possible reason for this may be that the adsorptions

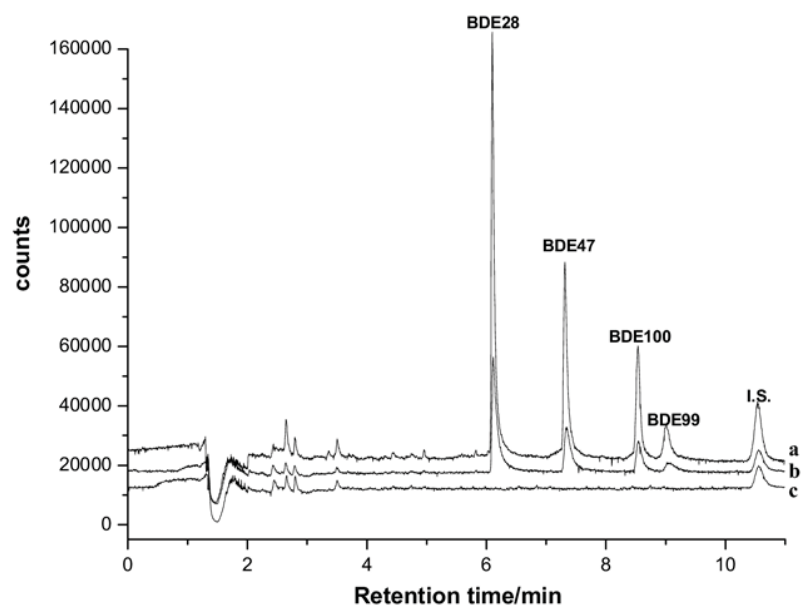

Figure 4. Chromatogram of the human serum sample obtained after HF-LPME with GC-ICP-MS. (a) Spiked $50 \mathrm{ng} / \mathrm{mL}$ human serum determined after 50-fold dilution; (b) spiked $10 \mathrm{ng} / \mathrm{mL}$ human serum determined after 10-fold dilution; (c) human serum determined after 10 -fold dilution. 
Table 5. Concentrations of PBDEs and recoveries in environmental samples

\begin{tabular}{|c|c|c|c|c|c|}
\hline \multicolumn{6}{|c|}{ East Lake water } \\
\hline \multirow[b]{2}{*}{ PBDEs } & \multirow[b]{2}{*}{ Added $\mathrm{ng} / \mathrm{mL}$} & \multirow[b]{2}{*}{ Found $\mathrm{ng} / \mathrm{mL}$} & \multirow[b]{2}{*}{ Recovery \% } & \multicolumn{2}{|c|}{$\mathrm{RSD}^{\mathrm{a}} / \%$} \\
\hline & & & & Retention time & Peak area \\
\hline \multirow[t]{2}{*}{ BDE-28 } & 0 & n.d. ${ }^{b}$ & - & - & - \\
\hline & 1 & 1.05 & 104.9 & 0.12 & 1.8 \\
\hline \multirow{2}{*}{ BDE-47 } & 0 & n.d. ${ }^{b}$ & - & - & - \\
\hline & 1 & 1.02 & 102.0 & 0.06 & 3.3 \\
\hline \multirow[t]{2}{*}{ BDE-99 } & 0 & n.d. ${ }^{b}$ & - & - & - \\
\hline & 1 & 1.00 & 99.5 & 0.08 & 3.2 \\
\hline \multirow[t]{2}{*}{ BDE-100 } & 0 & n.d. ${ }^{b}$ & - & - & - \\
\hline & 1 & 1.10 & 109.6 & 0.12 & 3.9 \\
\hline \multicolumn{6}{|l|}{ Soil } \\
\hline & & & & \multicolumn{2}{|c|}{$\mathrm{RSD}^{\mathrm{a}} \%$} \\
\hline PBDEs & Added ng/g & Found ng/g & Recovery \% & Retention time & Peak area \\
\hline \multirow[t]{2}{*}{ BDE-28 } & 0 & 26.48 & - & 0.02 & 6.1 \\
\hline & 20 & 48.66 & 110.9 & 0.02 & 5.3 \\
\hline \multirow[t]{2}{*}{ BDE-47 } & 0 & 172.2 & - & 0.08 & 2.0 \\
\hline & 20 & 189.5 & 86.7 & 0.02 & 2.3 \\
\hline \multirow[t]{2}{*}{ BDE-99 } & 0 & 18.74 & - & 0.08 & 6.8 \\
\hline & 20 & 36.44 & 88.5 & 0.01 & 10.4 \\
\hline \multirow[t]{2}{*}{ BDE-100 } & 0 & 87.42 & - & 0.13 & 3.2 \\
\hline & 20 & 104.8 & 86.9 & 0.24 & 3.7 \\
\hline \multicolumn{6}{|l|}{ Dust } \\
\hline & & & & \multicolumn{2}{|c|}{$\mathrm{RSD}^{\mathrm{a}} \%$} \\
\hline PBDEs & Added $\mu \mathrm{g} / \mathrm{g}$ & Found $\mu \mathrm{g} / \mathrm{g}$ & Recovery \% & Retention time & Peak area \\
\hline \multirow[t]{2}{*}{ BDE-28 } & 0 & 0.28 & - & 0.09 & 3.1 \\
\hline & 0.2 & 0.46 & 91.5 & 0.06 & 2.3 \\
\hline \multirow[t]{2}{*}{ BDE-47 } & 0 & 1.47 & - & 0.04 & 3.2 \\
\hline & 0.2 & 1.64 & 87.0 & 0.07 & 2.5 \\
\hline \multirow[t]{2}{*}{ BDE-99 } & 0 & 1.50 & - & 0.02 & 7.8 \\
\hline & 0.2 & 1.72 & 108.1 & 0.13 & 10.1 \\
\hline \multirow[t]{2}{*}{ BDE-100 } & 0 & 0.45 & - & 0.09 & 5.7 \\
\hline & 0.2 & 0.65 & 101.4 & 0.06 & 7.1 \\
\hline
\end{tabular}

${ }^{a} n=3$.

${ }^{b}$ n.d.: not detected.

in the glass walls are higher for the more apolar congeners of penta-BDE, congeners of BDE-99, and BDE-100, thus reducing the extraction efficiency.

\section{Comparison of HF-LPME-GC-ICP-MS with Other Methods}

The technique of HF-LPME only requires microliters of organic solvent; thus it could reduce the solvent consumption greatly compared with LLE and SPE. The cost for HF-LPME is negligible compared with the commercially prepared SPME fibers and SBSE stir bars. Also, the disposable nature of the hollow fiber eliminated the main problems commonly encountered with SPME and SBSE, such as carryover effects between analyses and limited lifetime. In addition, it does not require specialized apparatus like SPME and SBSE. Good sensitivity could be obtained with the extraction time of $20 \mathrm{~min}$ by
HF-LPME, while the extraction times of $60 \mathrm{~min}$ for HF-MMLLE, 30 to $60 \mathrm{~min}$ for HS-SPME, and $25 \mathrm{~h}$ for SBSE were needed, respectively, and much longer extraction times were needed with the other methods $[25,29-32]$ as shown in Table 3. So, HF-LPME is also very quick and suitable for rapid analysis. Compared with the method of HF-MMLLE [30], the proposed method is much simpler and faster, and has been successfully applied for the analysis of PBDEs in more complex matrix samples, such as human serum, soil, and dust.

ICP-MS has good sensitivity and selectivity compared with ECD or MS detection, which may cause identification or interference problems. A comparison of LODs for the four PBDEs obtained with different approaches is also shown in Table 3. The LODs of HF-LPME-GC-ICP-MS is comparable with the LODs listed here [20, 25, 29-35]. It should be noted that the 
LODs of this method could be improved further if the injection volume increased from $1 \mu \mathrm{L}$ (used in this work) to 2 to $3 \mu \mathrm{L}$.

\section{Application}

The proposed methodology was applied to check the presence of the investigated compounds in some real samples (human serum and environmental samples of lake water, soil from a landfill, and dust in a used computer). These samples were analyzed by HF-LPME with GC-ICP-MS under the optimized conditions.

Human serum. Due to the fact that the matrix of human serum is complex, sample dilution before analysis was performed to decrease the concentration of the interfering components. Therefore, 10- and 50-fold dilutions were investigated for the analysis of PBDEs in human serum. Three $\mathrm{mL}$ of the prepared sample was used for HF-LPME. The results showed that none of the target PBDEs (BDE-28, BDE-47, BDE-99, and BDE-100) was detected.

The recovery was defined as the percentage ratio between concentration of analyte found and concentration of analyte added. Each sample was analyzed three times and the recoveries calculated. It could be seen that the recoveries ranging from $84.5 \%$ to $111.7 \%$ and RSDs from $0.06 \%$ to $0.65 \%$ for retention time and from $1.3 \%$ to $7.5 \%$ for peak area after 10 -fold dilution were obtained by HF-LPME, while the recoveries ranging from $96.3 \%$ to $106.2 \%$ and RSDs from $0.03 \%$ to $0.17 \%$ for retention time and from $0.4 \%$ to $5.9 \%$ for peak area were obtained after 50-fold dilution. These results are summarized in Table 4. The chromatogram obtained for the human serum sample after dilution analyzed by HF-LPME-GC-ICP-MS is shown in Figure 4. Matrix interference in human serum was more apparent with 10-fold dilution than that with 50-fold dilution, while the recoveries of the spiked human serum were not affected.

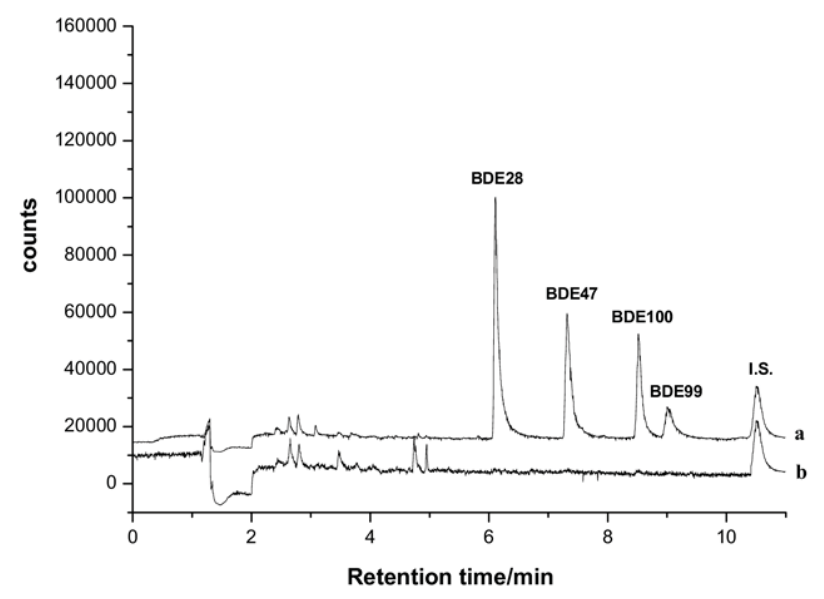

Figure 5. Chromatogram of the water sample obtained after HF-LPME with GC-ICP-MS. (a) Spiked $1 \mathrm{ng} / \mathrm{mL}$ East Lake water; (b) East Lake water.

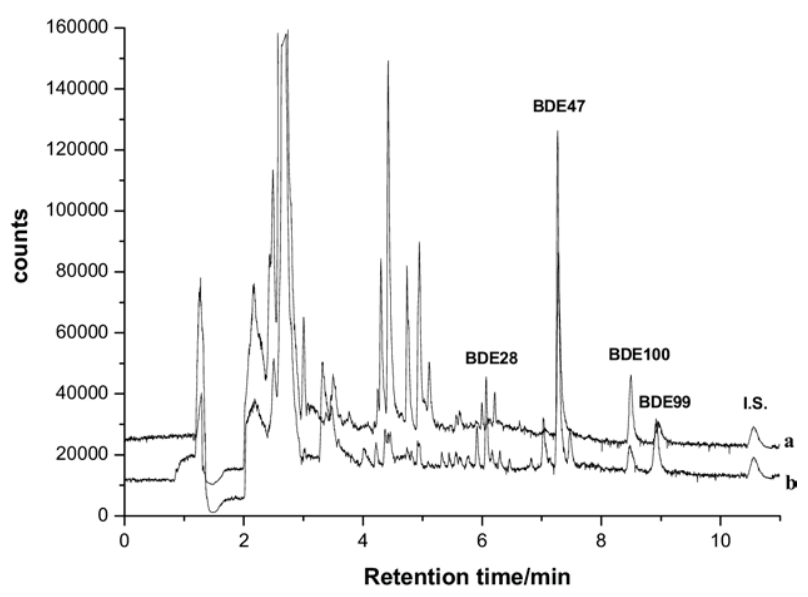

Figure 6. Chromatogram of the real soil and dust sample obtained after HF-LPME with GC-ICP-MS. (a) The soil sample; (b) the dust sample.

Environmental samples. The concentration of the four PBDEs in the East Lake water was also analyzed by the proposed method. Before the analysis, BB-153 (I.S.) and $3 \mathrm{~mL}$ methanol was added to the $7 \mathrm{~mL}$ water sample, then $3 \mathrm{~mL}$ of the prepared sample was added to the vial for HF-LPME. The results showed that none of PBDEs of interest was detected in the East Lake water. The recoveries ranging from $99.5 \%$ to $109.6 \%$ and RSDs from $0.06 \%$ to $0.12 \%$ for retention time and from $1.8 \%$ to $3.9 \%$ for peak area were obtained. These data are shown in Table 5. The chromatogram obtained for the East Lake water sample by the proposed method is depicted in Figure 5.

The soil from a landfill as well as dust from a used computer was also analyzed by the developed method, and the chromatograms obtained are shown in Figure 6. The concentration of PBDEs found in the soil sample was $26.48 \mathrm{ng} / \mathrm{g}$ BDE-28, $172.19 \mathrm{ng} / \mathrm{g}$ BDE-47, 18.74 $\mathrm{ng} / \mathrm{g}$ BDE-99, and $87.42 \mathrm{ng} / \mathrm{g}$ BDE-100. The recoveries were between $86.7 \%$ and $110.9 \%$, RSDs were $0.01 \%$ $0.24 \%$ for retention time and $2.0 \% \sim 10.4 \%$ for peak area. And the concentration of PBDEs found in the dust sample was $0.28 \mu \mathrm{g} / \mathrm{g}$ BDE-28, $1.47 \mu \mathrm{g} / \mathrm{g}$ BDE-47, 1.50 $\mu \mathrm{g} / \mathrm{g}$ BDE-99, and $0.45 \mu \mathrm{g} / \mathrm{g}$ BDE-100. The recoveries were between $87.0 \%$ and $108.1 \%$, and RSDs were $0.02 \% \sim 0.13 \%$ for retention time and $2.3 \% \sim 10.1 \%$ for peak area (Table 5). It should be mentioned that GCICP-MS requires pure standards to be able to identify the other brominated peaks in the soil and dust samples via their retention times.

\section{Conclusions}

A sensitive and selective analytical method of HFLPME combined with GC-ICP-MS has been presented in this study as a viable approach for the determination of PBDEs in human serum and environmental samples. The proposed HF-LPME procedure enables the extraction of target analytes from complex matrix, and pro- 
vides an alternative sample preparation for the analysis of PBDEs. In comparison with conventional LLE and SPE, HF-LPME only requires microliters of organic solvent, thus greatly reducing the solvent consumption. Thus, it is environmentally friendly and is especially suitable for the analysis of small amounts of sample (such as human serum). Compared with SPME and SBSE, the proposed method is simple, fast, inexpensive, and can avoid the carry-over and cross-contamination associated with SPME and SBSE because the hollow fiber can be discarded after each extraction. In this work, PBDEs have been determined in soil, dust, spiked lake water, and human serum samples with satisfactory results. It demonstrated that HF-LPME-GC-ICP-MS is an effective method for the analysis of PBDEs in environmental and biological samples with complicated matrix.

\section{Acknowledgments}

The authors gratefully acknowledge financial support from the Science Fund for Creative Research Groups of NSFC (20621502), National Nature Science Foundation of China (20575048, 20375030), and MOE of China (NCET-04-0658).

\section{References}

1. Alaee, M.; Wenning, R. J. The Significance of Brominated Flame Retardants in the Environment: Current Understanding, Issues, and Challenges. Chemosphere 2002, 46, 579-582.

2. Pohlein, M.; Llopis, A. S.; Wolf, M.; van Eldik, R. Rapid Identification of RoHS-Relevant Flame Retardants from Polymer Housings by Ultrasonic Extraction and RP-HPLC/UV. J. Chromatogr. A 2005, 1066, 111117.

3. Labadie, P.; Budzinski, H. Alteration of Steroid Hormone Balance in Juvenile Turbot (Psetta maxima) Exposed to Nonylphenol, Bisphenol A, Tetrabromodiphenyl Ether 47, Diallylphthalate, Oil, and Oil Spiked with Alkylphenols. Arch. Environ. Contam. Toxicol. 2006, 50, 552-561.

4. Thomsen, C.; Lundanes, E.; Becher, G. Brominated Flame Retardants in Archived Serum Samples from Norway: A study on Temporal Trends and the Role of Age. Environ. Sci. Technol. 2002, 36, 1414-1418.

5. Eljarrat, E.; de la Cal, A.; Barcelo, D. Determination of Decabromodiphenyl Ether in Sediments Using Selective Pressurized Liquid Extraction Followed by GC-NCI-MS. Anal. Bioanal. Chem. 2004, 378, 610-614.

6. de la Cal, A.; Eljarrat, E.; Barcelo, D. Determination of 39 Polybrominated Diphenyl Ether Congeners in Sediment Samples Using Fast Selective Pressurized Liquid Extraction and Purification. J. Chromatogr. A 2003, 1021, 165-173.

7. Li, Q. Q.; Loganath, A.; Chong, Y. S.; Obbard, J. P. Determination and Occurrence of Polybrominated Diphenyl Ethers in Maternal Adipose Tissue from Inhabitants of Singapore. J. Chromatogr. B 2005, 819, 253-257

8. Ulrich, S. Solid-Phase Microextraction in Biomedical Analysis. J. Chromatogr. A 2000, 902, 167-194.

9. Krutz, L. J.; Senseman, S. A.; Sciumbato, . A. S. Solid-Phase Microextraction for Herbicide Determination in Environmental Samples. J. Chromatogr. A 2003, 999, 103-121.

10. Kolahgar, B.; Hoffmann, A.; Heiden, A. C. Application of Stir Bar Sorptive Extraction to the Determination of Polycyclic Aromatic Hydrocarbons in Aqueous Samples. J. Chromatogr. A 2002, 963, 225-230.

11. Jeannot, M. A.; Cantwell, F. F. Solvent Microextraction Into a Single Drop. Anal. Chem. 1996, 68, 2236-2240.

12. Jeannot, M. A.; Cantwell, F. F. Mass Transfer Characteristics of Solvent Extraction Into a Single Drop at the Tip of a Syringe Needle. Anal. Chem. 1997, 69, 235-239.

13. Pedersen-Bjergaard, S.; Rasmussen, K. E. Liquid-Liquid-Liquid Microextraction for Sample Preparation of Biological Fluids Prior to Capillary Electrophoresis. Anal. Chem. 1999, 71, 2650-2656.

14. Richoll, S. M.; Colon, I. Determination of Triphenylphosphine Oxide in Active Pharmaceutical Ingredients by Hollow-Fiber Liquid-Phase Microextraction Followed by Reversed-Phase Liquid Chromatography. J. Chromatogr. A 2006, 1127, 147-153.
15. Chia, K. J.; Huang, S. D. Simultaneous Derivatization and Extraction of Primary Amines in River Water with Dynamic Hollow-Fiber LiquidPhase Microextraction Followed by Gas Chromatography-Mass Spectrometric Detection. J. Chromatogr. A 2006, 1103, 158-161.

16. Zhao, L.; Lee, H. K. Liquid-Phase Microextraction Combined with HollowFiber as a Sample Preparation Technique Prior to Gas ChromatographyMass Spectrometry. Anal. Chem. 2002, 74, 2486-2492.

17. Shen, G.; Lee, H. K. Hollow-Fiber-Protected Liquid-Phase Microextraction of Triazine Herbicides. Anal. Chem. 2002, 74, 648-654.

18. Stapleton, H. M. Instrumental Methods and Challenges in Quantifying Polybrominated Diphenyl Ethers in Environmental Extracts: A Review. Anal. Bioanal. Chem. 2006, 386, 807-817.

19. Eljarrat, E.; de la Cal, A.; Barcelo, D. Potential Chlorinated and Brominated Interferences on the Polybrominated Diphenyl Ether Determinations by Gas Chromatography-Mass Spectrometry. J. Chromatogr. A 2003, 1008, 181-192.

20. Vonderheide, A. P.; Montes-Bayon, M; Caruso, J. A. Development and Application of a Method for the Analysis of Brominated Flame Retardants by Fast Gas Chromatography with Inductively Coupled Plasma Mass Spectrometric Detection. J. Anal. At. Spectrom. 2002, 17, 1480-1485.

21. Profrock, D.; Leonhard, P.; Wilbur, S.; Prange, A. Sensitive, Simultaneous Determination of $\mathrm{P}, \mathrm{S}, \mathrm{Cl}, \mathrm{Br}$, and I Containing Pesticides in Environmental Samples by GC Hyphenated with Collision-Cell ICPMS. J. Anal. At. Spectrom. 2004, 19, 623-631.

22. Meija, J.; Montes-Bayon, M.; Le Duc, D. L.; Terry, N.; Caruso, J. A. Simultaneous Monitoring of Volatile Selenium and Sulfur Species from Se Accumulating Plants (Wild Type and Genetically Modified) by GC/MS and GC/ICPMS Using Solid-Phase Microextraction for Sample Introduction. Anal. Chem. 2002, 74, 5837-5844.

23. Leon, V. M.; Alvarez, B.; Cobollo, M. A.; Munoz, S.; Valor, I. Analysis of 35 Priority Semivolatile Compounds in Water by Stir Bar Sorptive Extraction-Thermal Desorption-Gas Chromatography-Mass Spectrometry: I. Method Optimization. J. Chromatogr. A 2003, 999, 91-101.

24. Popp, P.; Keil, P.; Montero, L.; Ruckert, M. Optimized Method for the Determination of 25 Polychlorinated Biphenyls in Water Samples Using Stir Bar Sorptive Extraction Followed by Thermodesorption-Gas Chromatography-Mass Spectrometry. I. Chromatoor. A 2005, 1071, 155-162.

25. Llorca-Porcel, J.; Martinez-Sanchez, G.; Alvarez, B.; Cobollo, M. A.; Valor, I. Analysis of Nine Polybrominated Diphenyl Ethers in Water Samples by Means of Stir Bar Sorptive Extraction-Thermal DesorptionGas Chromatography-Mass Spectrometry. Anal. Chim. Acta 2006, 569, 113-118.

26. Barcelo, D. Environmental Protection Agency and Other Methods for the Determination of Priority Pesticides and Their Transformation Products in Water. J. Chromatogr. A 1993, 643, 117-143.

27. Jeannot, M. A.; Cantwell, F. F. Solvent Microextraction as a Speciation Tool: Determination of Free Progesterone in a Protein Solution. Anal. Chem. 1997, 69, 2935-2940.

28. Casado, A. G.; Rodriguez, L. C.; Hernandez, E. A.; Vilchez, J. L. Estimate of Gas Chromatographic Blanks Application to Detection Limits Evaluation as Recommended by IUPAC. J. Chromatogr. A 1996, 726, 133-139.

29. Polo, M.; Gomez-Noya, G.; Quintana, J. B.; Llompart, M.; GarciaJares, C.; Cela, R. Development of a Solid-Phase Microextraction Gas Chromatography/Tandem Mass Spectrometry Method for Polybrominated Diphenyl Ethers and Polybrominated Biphenyls in Water Samples. Anal. Chem. 2004, 76, 1054-1062.

30. Fontanals, N.; Barri, T.; Bergstrom, S.; Jonsson, J. A. Determination of Polybrominated Diphenyl Ethers at Trace Levels in Environmental Waters Using Hollow-Fiber Microporous Membrane Liquid-Liquid Extraction and Gas Chromatography-Mass Spectrometry. J. Chromatogr. A 2006, 1133, 41-48.

31. Salgado-Petinal, C.; Garcia-Chao, M.; Llompart, M.; Garcia-Jares, C. Cela, R. Headspace Solid-Phase Microextraction Gas Chromatography Tandem Mass Spectrometry for the Determination of Brominated Flame Retardants in Environmental Solid Samples. Anal. Bioanal. Chem. 2006, 385, 637-644.

32. Salgado-Petinal, C.; Llompart, M.; Garcia-Jares, C.; Garcia-Chao, M. Cela, R. Simple Approach for the Determination of Brominated Flame Retardants in Environmental Solid Samples Based on Solvent Extraction and Solid-Phase Microextraction Followed by Gas ChromatographyTandem Mass Spectrometry. J. Chromatogr. A 2006, 1124, 139-147.

33. Gomara, B.; Garcia-Ruiz, C.; Gonzalez, M. J.; Marina, M. L. Fractionation of Chlorinated and Brominated Persistent Organic Pollutants in Several Food Samples by Pyranyl-Silica Liquid Chromatography Prior to GC-MS Determination. Anal. Chim. Acta 2006, 565, 208-213.

34. Yusa, V.; Pardo, O.; Pastor, A.; de la Guardia, M. Optimization of a Microwave-Assisted Extraction Large-Volume Injection and Gas Chromatography-Ion Trap Mass Spectrometry Procedure for the Determination of Polybrominated Diphenyl Ethers, Polybrominated Biphenyls, and Polychlorinated Naphthalenes in Sediments. Anal. Chim. Acta 2006, 557, 304-313.

35. Herzke, D.; Gabrielsen, G. W.; Evenset, A.; Burkow, I. C. Polychlorinated Camphenes (Toxaphenes), Polybrominated Diphenylethers, and Other Halogenated Organic Pollutants in Glaucus gull (Larus hyperboreus) from Svalbard and Bjørnøya (Bear Island). Environ. Pollut. 2003 $121,293-300$. 